\title{
COVID-19 Update: The Future of Vaccine Treatments for Infants and Children
}

Darby O'Donnell, JD and the AfPA Governmental Affairs Team Alliance for Patient Access (AfPA)

The Alliance for Patient Access (allianceforpatientaccess.org), founded in 2006, is a national network of physicians dedicated to ensuring patient access to approved therapies and appropriate clinical care. AfPA accomplishes this mission by recruiting, training and mobilizing policy-minded physicians to be effective advocates for patient access. AfPA is organized as a non-profit 501(c)(4) corporation and headed by an independent board of directors. Its physician leadership is supported by policy advocacy management and public affairs consultants. In 2012, AfPA established the Institute for Patient Access (IfPA), a related 501(c) (3) non-profit corporation. In keeping with its mission to promote a better understanding of the benefits of the physician-patient relationship in the provision of quality healthcare, IfPA sponsors policy research and educational programming.

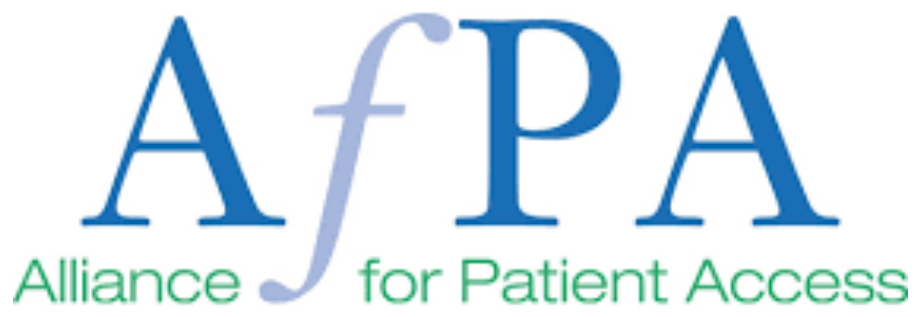

Since the rise of COVID-19 infections in the United States this past March, parents/guardians of children have faced a difficult number of questions regarding isolation versus socialization. For example: Is it safe to ... leave the house? Go to school? Play with other children? Visit elderly relatives?

In recent months, government entities and healthcare professional organizations have provided guidance for American families on mitigation of the virus, wellness, and safety. Even more, are being issued as the country returns to familiar social activities in the age of "social distancing."

During the stay at home orders, families have missed out on many scheduled events - including regular, well-care visits to the pediatrician focused on preventive treatments, such as vaccinations. In the midst of re-opening pediatric centers of care, children's hospitals, and other outpatient units, a heightened sensitivity has emerged for public safety and social distancing, in all public spaces. To coincide with these measures, however, doctors, health care professionals, and families are also beginning to focus on the issues of delayed care and missed health care appointments, and the implications it could have on patients and the public health in the future.

\section{"So, what is appropriate in this new \\ environment with regard to wellness visits, existing vaccines, and other preventive treatments, in the form of neonatal and childhood immunization, administered based on well-established schedules for babies and children?"}

So, what is appropriate in this new environment with regard to wellness visits, existing vaccines, and other preventive treatments, in the form of neonatal and childhood immunization, administered based on well-established schedules for babies and children? Should families delay childhood immunizations for the sake of safety during the COVID-19 pandemic, perhaps until there is a vaccine for that illness? Finally, what happens to those best practices associated with immunization for the last few decades particularly as young families contemplate the return to brick and mortar schools, if viable, in the fall?

\section{Societal Value Placed on Childhood Immunizations}

Adult patients are deferring or delaying care because they lack access to open facilities, the financial strain of the cost of treatment, or for fear of being infected with COVID-19 through interactions with the public. For children, like adults, this delay of care encompasses preventive care - namely immunization.

As pediatricians and neonatologists are aware, government entities and health professionals have collaborated (1) to establish birth through age 18 immunization schedule, (2) which the Centers for Disease Control and Prevention (CDC) publishes. The CDC estimates that for every $\$ 1$ invested in vaccines in the U.S., $\$ 10.20$ is saved in direct medical costs, according to the American Academy of Family Physicians (AAFP). (3)

Vaccines have been hotly debated by medical professionals, scientists, and American families for their usefulness and the possible consequences of administration. Without revisiting that debate, existing science and treatment outcomes support

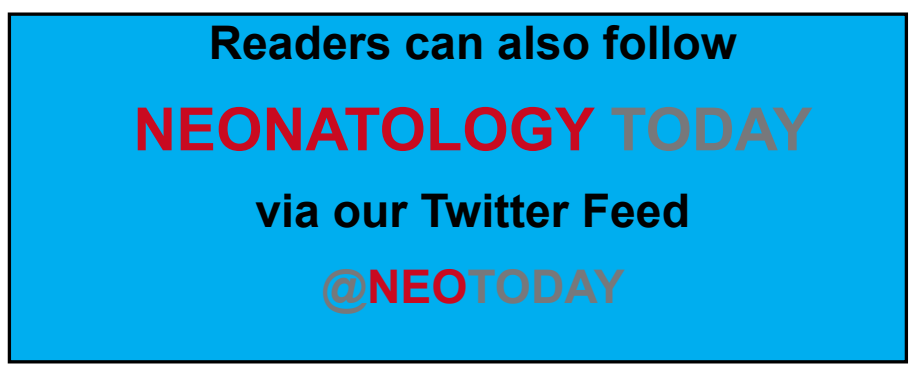


that vaccines have eradicated serious illnesses (4) through early intervention in American children - the most commonly known of these vaccinations being the polio vaccine.

For a more recent example, there was the measles outbreak in 2019. Measles is a highly contagious and serious disease that can be deadly. Prior to the recent outbreak, measles cases were relatively low. According to the Centers for Disease Control and Prevention (CDC), the majority of cases in the 2019 outbreak were among people who did not get a measles vaccination. (5)

Vaccines prevent disease. Some consider them better than a cure, and many researchers are in agreement that they are cost-effective. The World Health Organization estimates that immunization currently prevents 2-3 million deaths every year, (6) and suggests that 1.5 million more deaths could be avoided if global vaccination coverage increases.

"Vaccines prevent disease. Some consider them better than a cure, and many researchers are in agreement that they are cost-effective. The World Health Organization estimates that immunization currently prevents 2-3 million deaths every year, (6) and suggests that 1.5 million more deaths could be avoided if global vaccination coverage increases."

\section{Recent AAP Guidance}

The American Academy of Pediatrics (AAP) put out "Guidance on Providing Pediatric Well-Care During COVID-19" (7) last month, recognizing the challenge when immunizations are missed. The Academy acknowledges that "concern exists that delays in vaccinations [since the onset of COVID-19], may result in secondary outbreaks with vaccine-preventable illnesses."

The advent of telehealth and the recent surge in telemedicine use

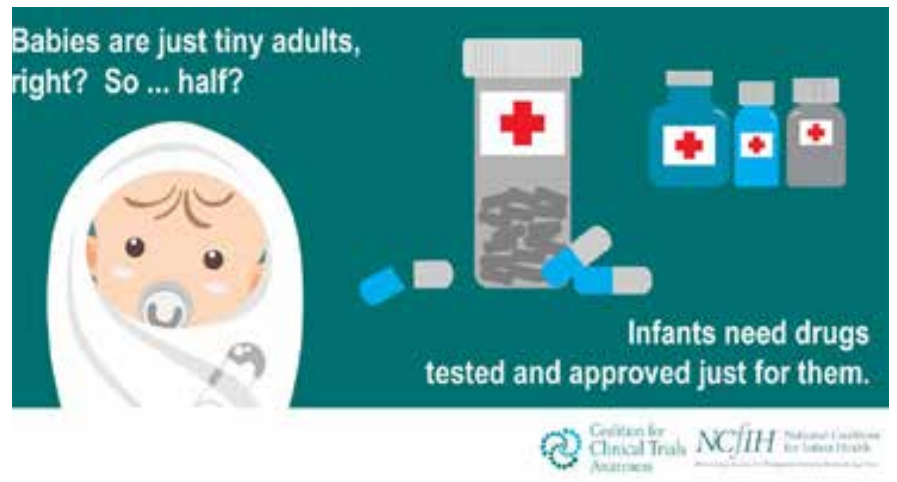

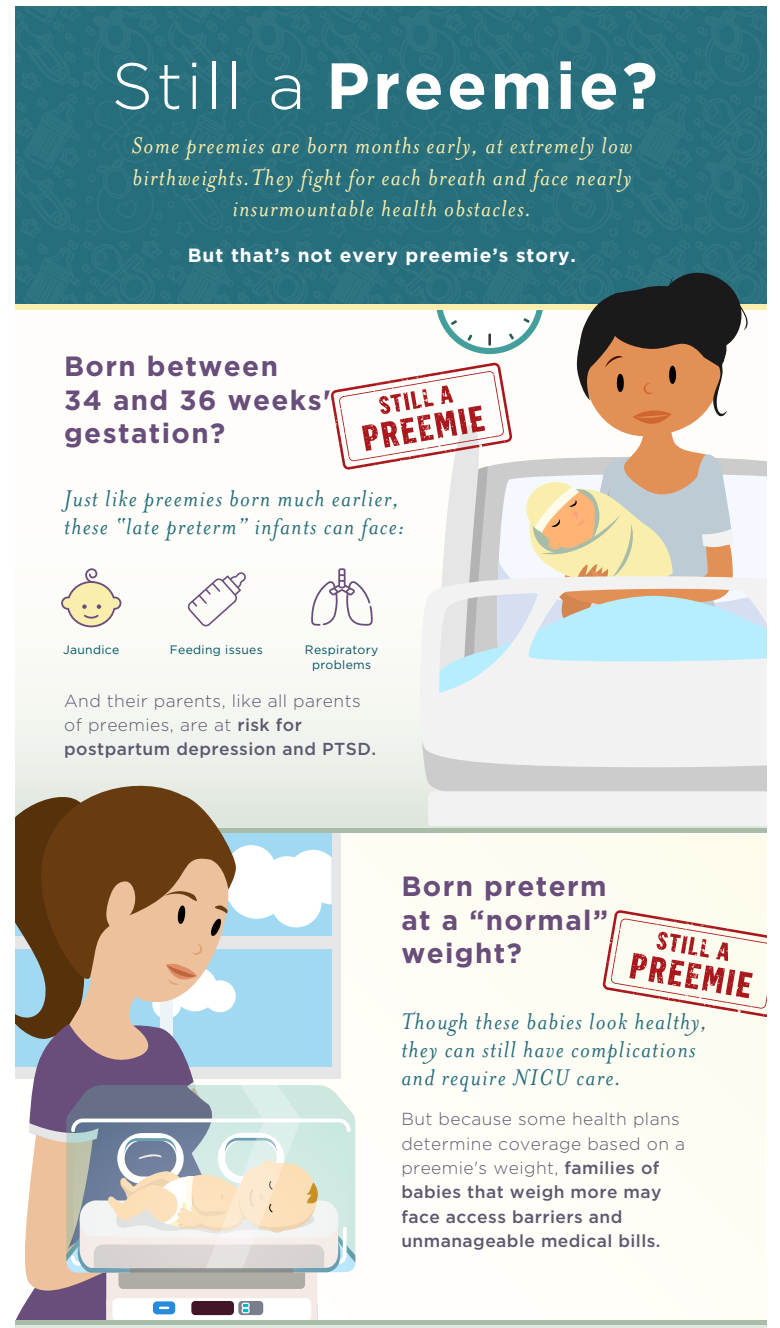
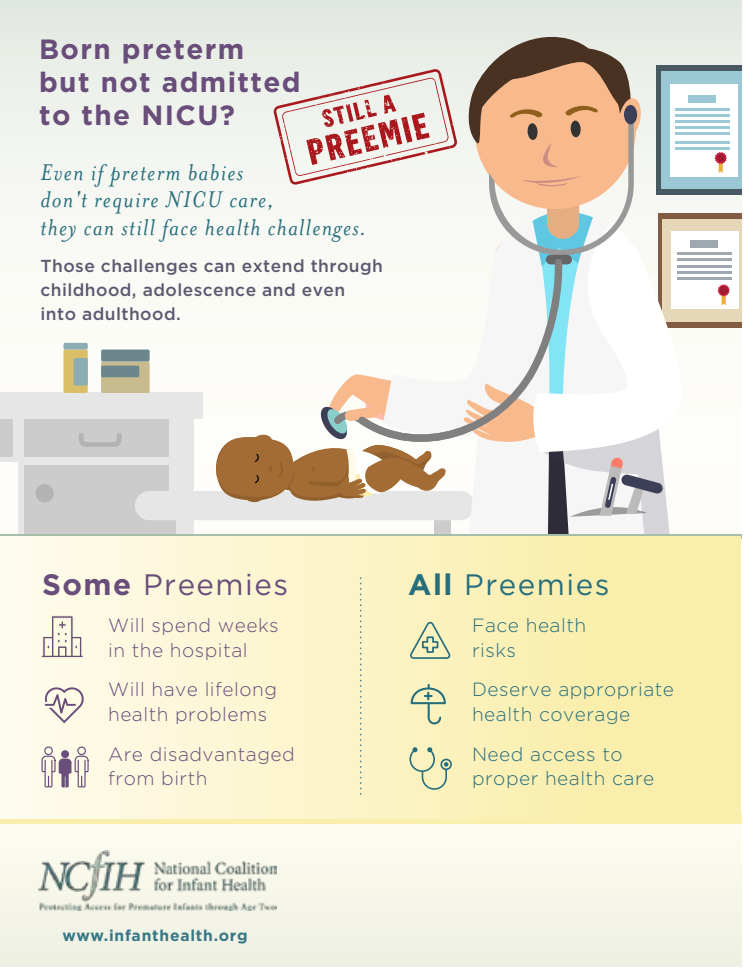
- and modified health insurance coverage plans for it - has been a great improvement in allowing patients of all ages to continue their healthcare routine during the coronavirus outbreak. Yet, the current technology is not capable of administering childhood immunizations directly. That still requires a physical location, (8) such as a parking lot staffed by health care professionals, as the stand-in for an in-person visit. However, technology may be imperative to documenting "state-based immunization information" to support pediatricians as they get their patients back on schedule, so to speak, according to the AAP.

The report goes on to provide suggestions to ensure safety for those in-person visits. AAP suggests measures such as scheduling well visits for children in one area of the facility of the clinic, or scheduling certain days of the week for alternating well patient visits with sick patients visits. Practically speaking, however, with family-centered care facilities and smaller, private clinics currently facing furloughs, layoffs, and other impacts on staff, this separation solution may prove difficult to execute. The AAP also suggests "collaborating with providers in the community to identify separate locations for providing well visits for children."

\section{Back to School \& Daycare}

Another pressing concern for the families of school-aged children: exposure to another child who has not been vaccinated or missed vaccinations during COVID-19. Parents may feel pressured to move quickly over the summer to catch up on the required vaccination schedule before the typical, August-September start of the school calendar.

State-based immunization laws inform school and daycare requirements and reflect guidance from The Advisory Committee on Immunization Practices (ACIP) (9) and their written recommendations on vaccine schedules, according to the National Conference of State Legislators. (10) These state laws are subject to exemptions, such as an intervening medical reason to skip the immunization, however.

Of greater societal concern, families who are jobless due to the health pandemic or cannot afford wellness care visits for the family may struggle with access to get their child vaccinated. Fortunately, a roadmap exists to help those families. In 1994, the Vaccines for Children program (VFC) (11) was "launched in direct response to a measles resurgence in the U.S. that caused tens of thousands of cases and over a hundred deaths, despite the availability of a measles vaccine since 1963." (12) The VFC program provides vaccines to children at no cost to families that might not otherwise get their child vaccinated based on affordability. There are also state programs that supplement the federal VFC fund. For more information on the VFC program statistics, see https://www.cdc. gov/media/releases/2014/images/p0424-immunization-program. pdf 913)

\section{Conclusion}

The CDC estimates that vaccinations will prevent more than $\underline{21}$ million hospitalizations and 732,000 deaths among children born in the last 20 years. (14)

The COVID-19 pandemic has impacted the number of children getting vaccinated, but the recommended infant and childhood vaccines still hold value - they have been proven to keep Americans safe and healthy. Hopefully, this delay in pediatric care will not be so great to overcome. Nevertheless, for the time being, it may prove to be yet another, unforeseen, trickle-down effect of the COVID-19 pandemic.

\section{References:}

1. https://www.aafp.org/patient-care/public-health/immunizations.html

2. https://www.aafp.org/patient-care/public-health/immunizations.html

3. https://www.aafp.org/patient-care/public-health/immunizations/schedules/child-schedule.html

4. https://www.aafp.org/patient-care/public-health/immunizations.html

5. https://www.cdc.gov/vaccines/parents/diseases/forgot14-diseases.html

6. https://familydoctor.org/childhood-vaccines-what-they-areand-why-your-child-needs-them/

7. https://www.who.int/news-room/facts-in-pictures/detail/immunization

8. https://services.aap.org/en/pages/2019-novel-coronaviruscovid-19-infections/clinical-guidance/guidance-on-providingpediatric-well-care-during-covid-19/

9. https://www. a afp.org/news/health-of-thepublic/20200323covidtelehealth.html

10. https://www.cdc.gov/vaccines/acip/recommendations.html

11. https://www.ncsl.org/research/health/immunizations-policyissues-overview.aspx

12. https://www.cdc.gov/media/releases/2014/p0424-immunization-program.html

13. https://www.cdc.gov/media/releases/2014/images/p0424-immunization-program.pdf

14. https://www.ncsl.org/research/health/immunizations-policyissues-overview.aspx

The author has not indicated any disclosures.

NT

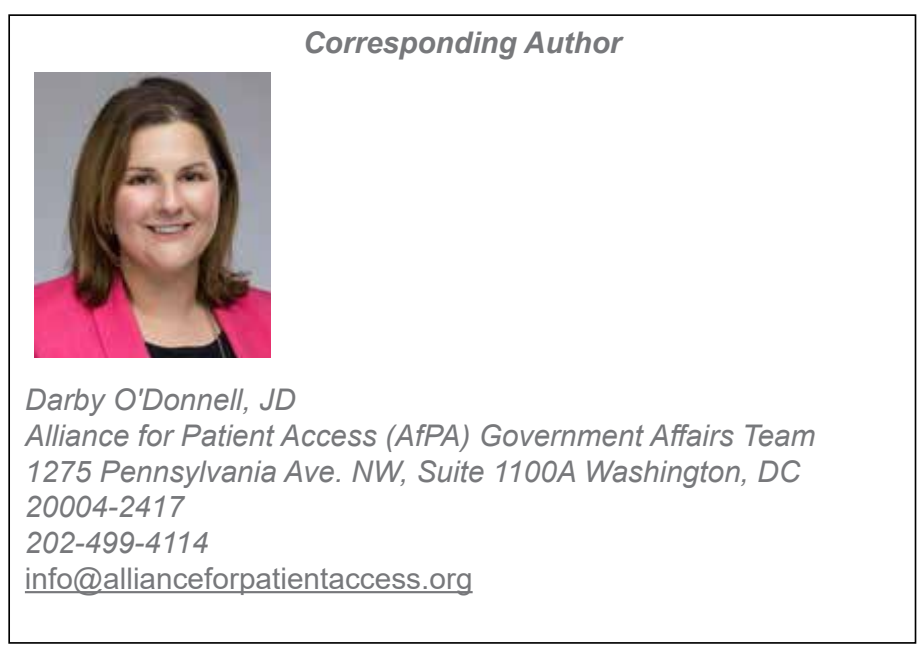

